\title{
Self-Reported Use and Attitudes Toward Performance-Enhancing Drugs in Ultramarathon Running
}

\author{
Michael D. Campian, DO; Alexandra E. Flis, MD; Masaru Teramoto, PhD, MPH; Daniel M. Cushman, MD \\ From the Division of Physical Medicine \& Rehabilitation, University of Utah, Salt Lake City, UT.
}

Introduction-The use of performance enhancing drugs (PEDs) has been reported in several sports. There have been no peer-reviewed articles on the use of PEDs in ultramarathon running. This study was to examine the use of PEDs in ultramarathon running and to identify attitudes and beliefs about the usage of PEDs in the sport.

Methods-An online survey was developed. The survey was distributed to potential participants through Ultrasignup and the Western States Endurance Run Facebook sites. The survey included 9 demographic questions, 11 PED questions, and a previously validated 17-item performance enhancement attitude scale (PEAS).

Results-Six hundred nine self-identified ultramarathon runners completed the survey; $8.4 \%$ of respondents reported using PEDs during competition or training. Cannabinoids, narcotics, and stimulants were the PEDs that were most frequently reported. There was no difference between sex, age, country of origin, rank, miles/week of training, or longest race between those that reported using PEDs and those that did not report using PEDs. There was, however, a significant difference in athletes who reported they knew another ultramarathon runner who had used PEDs to have significantly higher years of participation and ranked in the top 20th percentile. There additionally was an increased PEAS score of individuals who reported using a PED or individuals that knew an individual who used PEDs.

Conclusion-PEDs are being used in ultramarathon running. The exact extent of the use of PEDs in ultramarathon running is still unknown and challenging to fully investigate without formal, random testing, which is expensive and technically challenging.

Keywords: ultrarunning, doping, PED, cannabinoids, WADA, distance running

\section{Introduction}

Ultramarathon running is defined as any running race greater than $42.2 \mathrm{~km}$ (26.2 $\mathrm{mi})$ in distance. ${ }^{1}$ Common race distances include $50 \mathrm{~km}(31 \mathrm{mi}), 80 \mathrm{~km}(50 \mathrm{mi})$, $100 \mathrm{~km}$ (62 mi), $161 \mathrm{~km}$ (100 mi), and $322 \mathrm{~km}$ (200 mi). Relatively few scientific articles have been published relating to the sport, despite its view as being one of the ultimate tests of endurance. It is predominantly an amateur sport; however, it has gained significant interest over the past several decades both within the

Corresponding author: Michael D. Campian, DO, University of Utah, Division of Physical Medicine \& Rehabilitation, 590 Wakara Way, Salt Lake City, UT 84108; e-mail: michael.campian@hsc.utah. edu.

Submitted for publication November 2017

Accepted for publication April 2018.
United States and internationally. The sport saw an increase in more than 66,000 race finishes from 1980 to $2013 .^{2}$ With the increased popularity and competition of the sport of ultramarathon running, there is the opportunity to earn more sponsorship and prize money. ${ }^{3,4}$ As in other sports, with increasing popularity, international recognition (sponsorships), and monetary awards, there is the increased risk/pressure to use performance-enhancing substances to obtain a performance edge. $^{4}$

Performance-enhancing drug (PED) use has been well reported in other endurance sports. One study found that PED use is more common in individual sports compared with team sports, $14.4 \%$ to $7.4 \%$, respectfully. ${ }^{5}$ Additionally, there seems to be a higher prevalence in endurance athletes, with one study demonstrating that $37 \%$ of endurance athletes personally knew of an athlete 
using banned substances. ${ }^{6}$ The prevalence was higher than with "motor skills demanding events" and "team events," and similar to "speed and power events."

PED use in ultramarathon running is not well characterized. The sport as a whole has been largely devoid of doping scandals. ${ }^{4}$ However, over the past few years, several notable ultramarathon athletes have tested positive for PEDs: Gonzalo Calisto who tested positive for erythropoietin at his fifth place finish at the 2015 Ultra-Trail du Mont-Blanc, and Greg Vollet who tested positive for "banned stimulants" after his second place finish at the 2016 The Rut 50k. ${ }^{7}$ Before Calisto and Vollet testing positive, it was Elisa Desco who truly brought into question the use of PEDs to the forefront in ultramarathon running. She won the 2009 World Mountain Running Championship but was eventually stripped of her title after testing positive for erythropoietin. She was later banned for 2 years from competition by the International Association of Athletics Federations. ${ }^{4}$ However, in 2015 she participated in and completed The North Face Endurance Challenge 50-mile championship, bringing into question policies regarding racing after testing positive for PEDs.

Kurt referred to the antidoping policies in trail running as the "Wild West." Antidoping initiatives in endurance sports are starting to emerge, for example, the Clean Sport Collective. ${ }^{8}$ There are now at least 2 races that have adopted policies regarding a clean sport: the North Face Endurance Challenge Series (ECS) and Western States Endurance Run. ${ }^{9}$ For the ECS, an athlete banned by the International Association of Athletics Federations, World Anti-Doping Agency (WADA), US Anti-Doping Agency, or any national sports federation is prohibited from competing at any ECS race. Once the ban has been lifted, they can participate but are not eligible to receive prize money, awards, podium recognition, or competitive rankings. ${ }^{10}$ For the Western States Endurance Run, a lifetime ban from the race is given to an athlete who is caught violating antidoping rules or policies. ${ }^{11}$ On March 22, 2017, Salomon announced its Clean Sport and Athlete Transparency Initiative. ${ }^{3}$ Salomon will randomly test 16 top Salomon athletes up to 10 times per year using the independent Quartz program affiliated with Athletes for Transparency and International Trail Running Association, in addition to other testing conducted by official agencies such as WADA. Quartz Program performs doping analysis for athletes and makes the results publically available. In addition to simply testing athletes, it will also focus on 5 of its major trail races. In 2017, it will allow optional testing for nonSalmon athletes, but in 2018 will require testing for all top-ranked Salomon and non-Salomon athletes. However, it will require testing of all podium finishers after the race. This is said to be one of the strictest and most transparent of any testing program by a sports brand or sports federation today.

Peer-reviewed literature on PED use in the sport has not been published to the authors' knowledge. In 2015, the first 2 informal studies were published on popular social media ultramarathon running blogs investigating the use of PEDs in ultramarathon running. ${ }^{12,13}$ The first study by Torrence asked a single question: "Have you ever used a PED while training for or participating in an organized ultramarathon (a running/hiking event/race of 50k in length or longer)?" He received 705 responses and found that $9 \%$ had used performance enhancing substances. ${ }^{13}$ In the second study, Bleakman expanded upon Torrence's study, investigating PED use in and out of competition, socially and for medical reasons. He received 551 responses for a total PED use of 30.2\%: $1.6 \%$ during competition, $2.4 \%$ outside competition, $15.5 \%$ socially, and $11.3 \%$ prescription. ${ }^{12}$ More recently, Bleakman published a follow-up study to his initial study in July 2015 that revealed that these numbers roughly doubled over the following year. ${ }^{14}$ Of note, none of these previous studies specifically addressed which types of PEDs were being used, however, just if PEDs were being used.

Besides the use of PEDs in the sport of ultramarathon running, little is also known regarding athletes' attitudes towards doping and ultramarathon running. There have been some articles in popular running magazines that have demonstrated distaste of use of PEDs in the sport of ultramarathon running. ${ }^{4}$ In other sports, varying views are taken, with most decrying their use, ${ }^{6,15-17}$ while a few embrace them. ${ }^{18}$ A 17-item, 6-point Likert-type scale on athletes' attitudes regarding doping, the performance enhancement attitude scale (PEAS), has been created and validated to better understand athletes' attitudes and behavioral intentions toward PEDs. ${ }^{19-21}$ The PEAS scale ranges from 17 to 102 , with midpoint being 59.5. ${ }^{19}$ Higher scores reflect more favorable attitudes toward PED use and vice versa lower score are less favorable. ${ }^{19}$

The aim of this survey is twofold. First is to attempt to better quantify the self-reported use of PEDs in ultramarathon running to include types of substances being utilized. Second is to examine attitudes and beliefs of ultramarathon runners towards use of PEDs in the sport.

\section{Methods}

After obtaining institutional review board exemption from University of Utah, a link to an anonymous, voluntary, compensation-free survey was distributed to ultramarathon runners through 2 social media sites, the 
Western States Endurance Run Facebook site and Ultrasignup Facebook site after permission was received by the site owners. Informed consent was obtained at the beginning or the survey. At the time the survey was sent out (2017), there were approximately 80,000 online users between the 2 sites who were potentially exposed to the survey, although an unknown percentage of these users actually viewed the survey. The survey was administered via REDCap, ${ }^{22}$ which is a secure, research-oriented online software system. The survey, available in its entirety in the online appendix, consisted of 9 demographic questions, 11 PED questions, and the 17-item PEAS. ${ }^{18-20}$ The questions were chosen threefold: 1 based on previous studies, 2 to specifically address the research questions purposed, and finally, questions of the authors that were not based on prior research. Informed consent was obtained before initiation of the survey, not allowing them to participate in the survey unless they agreed. Inclusion criteria consisted of runners participating in ultramarathons who were at least 18 years of age.

\section{DATA ANALYSIS}

Descriptive statistics (frequency and percentage for categorical variables, mean and standard deviation for quantitative variables) were calculated for the athlete profiles and PED use of ultramarathon runners. Athlete profiles were compared based on personal PED use and knowledge of PED use of other runners (= dichotomous categorical variables). A 2-by-2 contingency table analysis with a $\chi^{2}$ test and an independent $t$ test were used to examine categorical variables and quantitative variables of athlete profiles, respectively. Scores on the 17-item PEAS $^{19,20}$ were compared by personal PED use and knowledge of PED use of other runners using an independent $t$ test. For better understanding, mean PEAS scores, along with their standard deviations, were calculated and reported here. Cronbach's alpha was computed to examine internal consistency of PEAS. Furthermore, patterns of responses in individual PEAS items were examined by personal PED use and knowledge of PED. All significance tests described here were conducted using Monte Carlo permutation tests with 10,000 resamples with computations of empirical $P$ values. ${ }^{23}$ An alpha level of 0.05 was used as a threshold for statistical significance.

\section{Results}

The responses of 609 ultramarathon runners who fully completed the study were analyzed in this study. A total of 84 surveys were not included because the participant did not complete the survey in full. Data screening revealed that individual missing cases for any question did not exceed 5\% of the total sample size; therefore, all the responses from 609 runners regardless of missing cases were included in the analysis.

Demographic profiles of ultramarathon runners are summarized in Table 1. Table 2 and Figure 1 show the responses to personal PED use and knowledge in PED use of other ultramarathon runners, along with specific types of PEDs used by runners. Runners used cannabinoids, narcotics, stimulants, glucocorticoids, and anabolic agents, in descending frequency. Profiles by personal PED use and knowledge of PED use of other ultramarathon runners are summarized in Table 3. The $\chi^{2}$ test showed that there was no significant association of sex, age, country, rank, miles/week of training, or longest race distance completed to personal PED use $(P>0.05)$. Likewise, years of participation and average number of races/year over the last 3 years were not significantly different by personal PED use $(P>0.05)$. On the other hand, athletes who knew another

Table 1. Profiles of ultramarathon runners

\begin{tabular}{|c|c|}
\hline Variable & Frequency (\%) \\
\hline \multicolumn{2}{|l|}{ Sex } \\
\hline Male & $454(74.9)$ \\
\hline Female & $152(25.1)$ \\
\hline \multicolumn{2}{|l|}{ Age (y) } \\
\hline $18-30$ & $80(13.2)$ \\
\hline $31-40$ & $250(41.2)$ \\
\hline $41-50$ & $181(29.9)$ \\
\hline $51-60$ & $80(13.2)$ \\
\hline 61 and older & $15(2.5)$ \\
\hline \multicolumn{2}{|l|}{ Country } \\
\hline US & $527(86.5)$ \\
\hline Non-US & $82(13.5)$ \\
\hline \multicolumn{2}{|l|}{ Rank } \\
\hline Top 20 percentile & $142(25.1)$ \\
\hline Bottom 80 percentile & $423(74.9)$ \\
\hline \multicolumn{2}{|l|}{ Miles/Week of training } \\
\hline $1-25$ & $19(3.1)$ \\
\hline $26-50$ & $243(40.0)$ \\
\hline $51-75$ & $251(41.4)$ \\
\hline $76-100$ & $84(13.8)$ \\
\hline$>100$ & $10(1.7)$ \\
\hline \multicolumn{2}{|l|}{ Longest race distance competed } \\
\hline $50 \mathrm{~km}$ & $77(13.7)$ \\
\hline $50 \mathrm{mi}$ & $89(15.8)$ \\
\hline $100 \mathrm{~km}$ & $71(12.6)$ \\
\hline $100 \mathrm{mi}$ & $270(48.0)$ \\
\hline $200 \mathrm{mi}$ & $12(2.1)$ \\
\hline Other & $44(7.8)$ \\
\hline Number of races/year over last 3 years & $6.4(4.6)^{*}$ \\
\hline Years of participation & $6.7(6.0)^{*}$ \\
\hline
\end{tabular}

*Mean (SD). 
Table 2. Responses to personal performance-enhancing drug (PED) use and knowledge in PED use of other ultramarathon runners

\begin{tabular}{|c|c|c|}
\hline Question & Yes & No \\
\hline Ever used PEDs during ultramarathon race/training & $51(8.4)$ & $556(91.6)$ \\
\hline Personally know any ultramarathon runners having used PEDs (excluding yourself) & $112(18.5)$ & $494(81.5)$ \\
\hline Felt PEDs significantly improved your performance if you have ever used PEDs & $13(26.0)$ & $37(74.0)$ \\
\hline Ever used PEDs outside of ultramarathon for social reasons & $113(18.7)$ & $491(81.3)$ \\
\hline Ever used PEDs prescribed for medical reasons & $120(19.8)$ & $486(80.2)$ \\
\hline Would take a PED if it were made legal & $128(21.1)$ & $478(78.9)$ \\
\hline
\end{tabular}

Values are frequency $(\%)$.

ultramarathon runner that used PEDs (not themselves) had significantly higher years of participation than their counterparts $(8.1 \pm 6.4$ vs $6.3 \pm 5.7 \mathrm{y} ; t(541)=-2.76$; $P=0.010)$. Furthermore, a significantly greater number of athletes ranked in the top 20th percentile reported that they knew another ultramarathon runner that used PEDs compared with those ranked in the bottom 80th percentile $\left(25.4 \%\right.$ vs $\left.16.9 \% ; \chi^{2}(1)=4.97 ; P=0.026\right)$. There were no significant differences in any other variables of athlete profiles by knowledge of PED use of other runners $(P>0.05)$.

The independent $t$ test showed that PEAS scores among ultramarathon runners who reported that they had ever used PEDs during ultramarathon racing/training were significantly higher than the scores among those who reported otherwise (sum scores: $46.0 \pm 13.7$ vs $34.6 \pm 11.1$; mean scores: $2.7 \pm 0.8$ vs $2.0 \pm 0.7 ; P<0.001$; Table 3 ). Similarly, runners with personal knowledge of other ultramarathon runners having used PEDs (excluding themselves) had significantly higher PEAS scores than their counterparts (sum scores: $39.8 \pm 13.9$ vs $34.7 \pm 11.0$; mean scores: 2.3 \pm 0.8 vs $2.0 \pm 0.6 ; P<0.001)$. Cronbach's alpha of PEAS items (overall mean $=35.6$; overall $\mathrm{SD}=11.8$ ) was 0.863 , showing an acceptable internal consistency. ${ }^{24}$

\section{Discussion}

To our knowledge, this is the first scientific survey investigating PED use and attitudes towards use of PEDs in ultramarathon running. Our study has demonstrated that ultramarathon running is not immune to the use of PEDs. A total of $8.4 \%$ of individuals reported using PEDs during competition and/or training. This is quite similar to what Torrence and Bleakman found from their surveys, with $9.0 \%$ and $9.3 \%$, respectfully, admitting to the use of PEDs during training or in competition. ${ }^{13,14}$ Additionally, $18.7 \%$ of runners reported using PEDs socially and $19.8 \%$ of runners reported using PEDs for medical reasons.

The most commonly used PEDs were cannabinoids (13.3\%), narcotics $(6.4 \%)$, and stimulants $(3.0 \%)$. These results differ from other sports where more classically associated PEDs such as anabolic agents and peptide

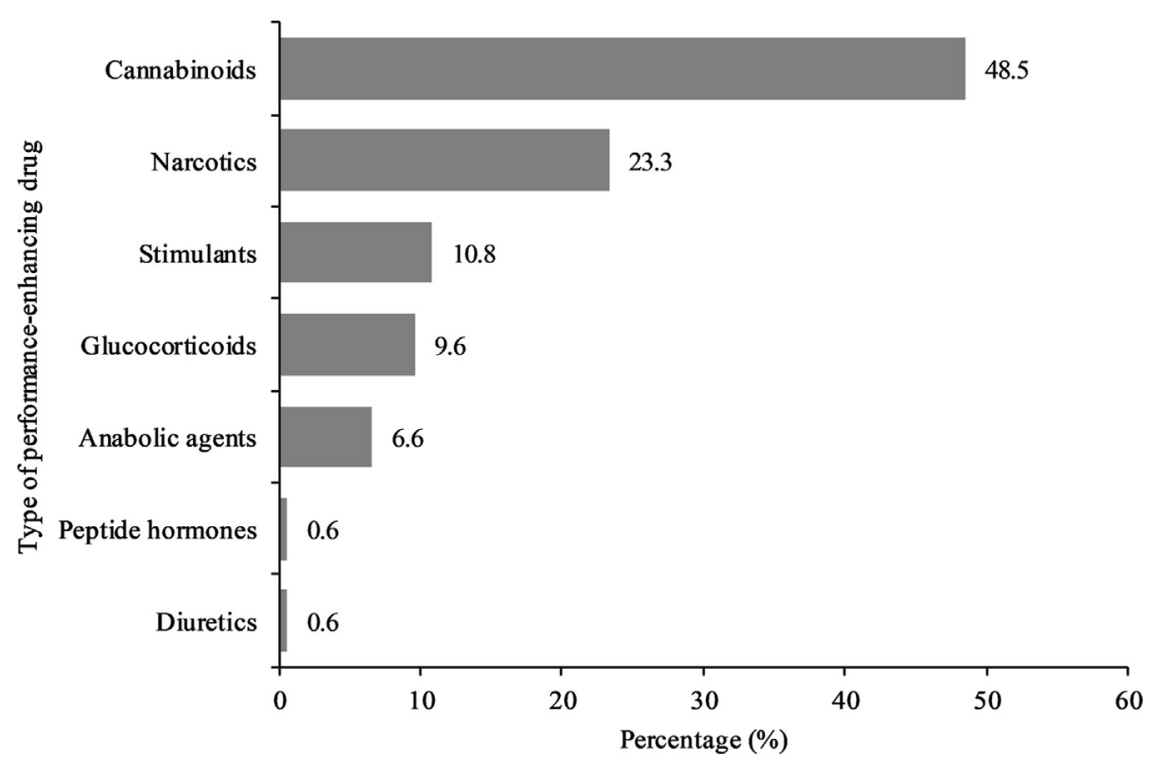

Figure 1. Specific types of performance-enhancing drugs used by runners. 
Table 3. Athlete profiles by personal performance-enhancing drug use and knowledge in performance-enhancing drug use of other ultramarathon runners.

\begin{tabular}{|c|c|c|c|c|c|c|}
\hline \multirow[b]{2}{*}{ Variable } & \multicolumn{3}{|c|}{$\begin{array}{l}\text { Ever used PEDs during } \\
\text { ultramarathon race/training }\end{array}$} & \multicolumn{3}{|c|}{$\begin{array}{c}\text { Personally know any ultramarathon } \\
\text { runners having used PEDs } \\
\text { (excluding yourself) }\end{array}$} \\
\hline & Yes & No & $\mathrm{P}$ & Yes & No & $\mathrm{P}$ \\
\hline \multicolumn{7}{|l|}{ Sex } \\
\hline Male & $40(8.8)$ & 412 (91.2) & \multirow[t]{2}{*}{0.540} & 79 (17.5) & $373(82.5)$ & \multirow[t]{2}{*}{0.305} \\
\hline Female & $11(7.2)$ & $141(92.8)$ & & $32(21.2)$ & $119(78.8)$ & \\
\hline \multicolumn{7}{|l|}{ Age (y) } \\
\hline $18-30$ & $10(12.5)$ & $70(87.5)$ & \multirow[t]{5}{*}{0.636} & $14(17.5)$ & $66(82.5)$ & \multirow[t]{5}{*}{0.900} \\
\hline $31-40$ & $19(7.6)$ & $231(92.4)$ & & $43.0(17.2)$ & $207.0(82.8)$ & \\
\hline $41-50$ & $13(7.2)$ & $167(92.8)$ & & $35(19.4)$ & $145(80.6)$ & \\
\hline $51-60$ & $8(10.0)$ & $72(90.0)$ & & $17(21.5)$ & $62(78.5)$ & \\
\hline 61 and older & $1(6.7)$ & $14(93.3)$ & & $2(14.3)$ & $12(85.7)$ & \\
\hline \multicolumn{7}{|l|}{ Country } \\
\hline US & $46(8.7)$ & $480(91.3)$ & \multirow[t]{2}{*}{0.516} & $100(19.0)$ & $425(81.0)$ & \multirow[t]{2}{*}{0.388} \\
\hline Non-US & $5(6.2)$ & $76(93.8)$ & & $12(14.8)$ & $69(85.2)$ & \\
\hline Years of participation (mean $[\mathrm{SD}]$ ) & $7.7(6.3)$ & $6.6(6.0)$ & 0.252 & $8.1(6.4)$ & $6.3(5.7)$ & 0.010 \\
\hline \multicolumn{7}{|l|}{ Rank } \\
\hline Top 20 percentile & $15(10.6)$ & $127(89.4)$ & \multirow[t]{2}{*}{0.316} & $36(25.4)$ & $106(74.6)$ & \multirow[t]{2}{*}{0.026} \\
\hline Bottom 80 percentile & $33(7.8)$ & $389(92.2)$ & & $71(16.9)$ & $350(83.1)$ & \\
\hline \multicolumn{7}{|l|}{ Miles/Week of training } \\
\hline $1-25$ & $1(5.6)$ & $17(94.4)$ & \multirow[t]{5}{*}{0.933} & $3(16.7)$ & $15(83.3)$ & \multirow[t]{5}{*}{0.070} \\
\hline $26-50$ & $19(7.8)$ & $224(92.2)$ & & $39(16.1)$ & $203(83.9)$ & \\
\hline $51-75$ & $21(8.4)$ & $229(91.6)$ & & $44(17.6)$ & $206(82.4)$ & \\
\hline $76-100$ & $9(10.7)$ & $75(89.3)$ & & $25(29.8)$ & $59(70.2)$ & \\
\hline$>100$ & $1(10.0)$ & $9(90.0)$ & & $1(10.0)$ & $9(90.0)$ & \\
\hline Number of races/year over last 3 years (mean $[\mathrm{SD}]$ ) & $6.1(4.3)$ & $6.4(4.6)$ & 0.678 & $6.1(4.2)$ & $6.4(4.6)$ & 0.542 \\
\hline \multicolumn{7}{|l|}{ Longest race distance competed } \\
\hline $50 \mathrm{~km}$ & $5(6.5)$ & $72(93.5)$ & \multirow[t]{6}{*}{0.072} & $11(14.3)$ & $66(85.7)$ & \multirow[t]{6}{*}{0.159} \\
\hline $50 \mathrm{mi}$ & $2(2.2)$ & $87(97.8)$ & & $11(12.4)$ & $78(87.6)$ & \\
\hline $100 \mathrm{~km}$ & $5(7.0)$ & $66(93.0)$ & & $10(14.1)$ & $61(85.9)$ & \\
\hline $100 \mathrm{mi}$ & $32(11.9)$ & $236(88.1)$ & & $57(21.2)$ & $212(78.8)$ & \\
\hline $200 \mathrm{mi}$ & $1(8.3)$ & $11(91.7)$ & & $4(33.3)$ & $8(66.7)$ & \\
\hline Other & $2(4.5)$ & $42(95.5)$ & & $10(23.8)$ & $32(76.2)$ & \\
\hline \multicolumn{7}{|l|}{ PEAS (mean [SD]) } \\
\hline Sum scores & $46.0(13.7)$ & $34.6(11.1)$ & \multirow[t]{2}{*}{$<0.001$} & 39.8 (13.9) & $34.7(11.0)$ & \multirow[t]{2}{*}{$<0.001$} \\
\hline Mean scores & $2.7(0.8)$ & $2.0(0.7)$ & & $2.3(0.8)$ & $2.0(0.6)$ & \\
\hline
\end{tabular}

PED, performance-enhancing drug; PEAS, performance enhancement attitude scale value.

Values are frequency $(\%)$ unless specified otherwise.

Note: Bolding is used to identify statistically significant contrasts.

hormones/growth factors are more heavily utilized. ${ }^{25}$ The evidence regarding the performance-enhancing effects of cannabinoids is still inconclusive. ${ }^{26}$ There has been evidence to support that it can improve vasodilation and bronchodilation, therefore oxygenation which could improve performance in ultramarathon running. ${ }^{27}$ Additionally, cannabinoids are known to improve nausea, stimulate appetite, and improve pain, which are common issues seen in ultramarathon runners. ${ }^{27,28}$ Conversely, cannabinoids increase heart rate, delay reaction times, decrease coordination, impair concentration and alter spatial awareness, which could be detrimental, for instance, resulting in falls or other musculoskeletal injury. ${ }^{27,29}$ Therefore, it is unclear if the benefits outweigh the risks. The endurance benefits from stimulants and narcotic pain medications are better understood..$^{30,31}$ The longer ultramarathon races are requiring participants to run through the night; stimulants can help to promote wakefulness and improved concentration during these portions of the race. Even more understandable, narcotic pain medications could alter a participant's pain tolerance. Less commonly reported substances were glucocorticoids $(3.0 \%)$ and anabolic steroids (2.0\%). Glucocorticoids can decrease inflammation systemically and locally, which 
can improve pain associated with musculoskeletal injuries, which could be potentially beneficial to ultramarathon runners with musculoskeletal injuries being prevalent. ${ }^{32}$ Anabolic steroids increase lean muscle mass and strength, which to some extent would benefit ultramarathon runners. ${ }^{33}$ However, too much mass can have ill effects with having to carry the extra mass during the race. It should be noted that PEDs very well may not be used solely for performance-enhancing effects; runners may simply be using them as a coping strategy, self-medication for mental health disorders, or recreationally. ${ }^{34}$

Another interesting finding from the survey is that only 1 individual reported using a diuretic. Diuretics are typically used as a masking agent for red blood cellproducing agents and as such have been used in other endurance sports as an advanced means of evading positive tests. There could be several reasons for this phenomenon. First, doping in ultramarathons does not appear to be as prevalent as in other sports and thus there is no need for a masking agent. More realistically, doping control is not commonly performed in ultramarathon races and as such, ultramarathon runners may not feel the need to alter their unmonitored hematologic profile.

In regards to PED use and ultramarathon running, there were several significant findings. Respondents who reported they knew another ultramarathon runner who was using PEDs had significantly higher years of participation (2 years) than their counterparts. This may be related to purely knowing more ultramarathon runners secondary to being involved in the ultramarathon community for a longer period of time. Ultramarathon running is still a relatively small sport, with fewer events offered than larger endurance sports like marathon running or cycling. There is a much better chance of meeting a larger percentage of runners in the sport including the more elite runners. It could be argued, however, that this small difference, although significant, may be of limited importance. The other significant finding was that individuals who reported to know an ultramarathon runner who had used PEDs where more likely to be ranked in the top 20th percentile. There is a great deal of potential reasons for this occurring. Ultramarathon running continues to be more competitive and runners in the top 20th percentile are using PEDs to gain that competitive edge. Additionally, runners in the top 20th percentile are more likely to be adversely affected by not performing well in regards to potential sponsorships, prize money, and/or national recognition.

In regards to attitudes towards PED use and ultramarathon running, there were also several significant findings. There was a significant increase in PEAS scores of 1) individuals reporting use of PEDs and 2) individuals who knew of an individual using PEDs. This means that individuals with self-reported use of PEDs or individuals who know of an individual who has used PEDs appear to be more lenient towards doping. This is consistent with previous findings. ${ }^{19}$ The first finding is somewhat intuitive; those who have used a PED are more lenient toward their use (and thus had a higher PEAS score). This may be a normalizing behavior, responding to the knowledge of a fellow ultramarathon runner using a PED by assuming that it cannot be too bad. Additionally, it is likely that the known PED user is a friend, and thus more likely to confide in their use. This openness may give the appearance of being less "serious" or harmful. Other sports show large variations in their attitudes toward PEDs, ${ }^{35-37}$ and these seem to point to individual cultural differences within sport type.

There are limitations with this study. There is the obvious selection bias associated with voluntary surveys; athletes who take PEDs may be less likely to participate in the survey or falsify answers out of fear of its potential lack of anonymity. As such, there is no way to verify accuracy of the responses. This additionally can also result in a lower response rate due to fear of adverse consequences from participation in the survey. Athletes may also not completely understand the questions being asked (eg, what is actually considered a PED, if these medications were truly being used for performance enhancement, etc.). Specifically, not every athlete is formally familiar with all the nuances of PEDs; recreational athletes, for example, may not appreciate every substance that is considered a PED. Some may believe if a physician is prescribing the medication then it is all right. Furthermore, if a substance is legal (eg, cannabis in many states), this can alter perceptions. The authors note that it is suggested in the literature, ${ }^{38}$ and anecdotal discussions with several ultramarathon runners reveal that they are unaware of the effects of several of these medications, but it was not explicitly studied here.

This is an initial investigation into the prevalence and attitudes of PED use in ultramarathon runners. We opted to use open-ended responses in some locations for more broad data collection at the risk of diminishing accuracy. This could also potentially decrease the positive responses due to perceived effort of typing out responses to openended questions. More sophisticated and accurate studies need to be performed to better understand what is happening from a PED standpoint in ultramarathon running.

\section{Conclusion}

Ultramarathon running appears not be void of problems with the use of PEDs. The exact extent of the use of PEDs in ultramarathon running is still unknown and 
challenging to fully investigate without formal, random testing which is expensive and technically challenging.

Acknowledgments: The authors thank Western States Endurance Run and Ultrasignup.com for their access and support.

Author Contributions: Study concept and design (MC, DMC, AEF, MT); acquisition of data (MC, DMC, AEF, MT); analysis of data (MC, DMC, MT); drafting of manuscript (MC, DMC, AEF, MT); revision of manuscript (MC, DMC, MT); approval of final manuscript (MC, DMC, AEF, MT).

Financial/Material Support: None.

Disclosures: None.

\section{Supplementary Materials}

Supplementary material cited in this article is available online at http://dx.doi.org/10.1016/j.wem.2018.04.004.

\section{References}

1. Ultrarunning Magazine. What is ultra running? Available at: https://www.ultrarunning.com/features/what-is-ultrarunning/. 2016. Accessed September 1, 2017.

2. Ultrarunning Magazine. 2013 Ultrarunning participation by the numbers. Available at: https://www.ultrarunning. com/featured/2013-ultrarunning-participation-by-the-num bers/. 2016. Accessed September 1, 2017.

3. Winebaum S. Salomon launches clean sport and athlete transparency initiative. Available at: http://running.com petitor.com/2017/03/news/salomon-launches-clean-spor t-athlete-transparency-initiative_163088.\%202017. Accessed February 4, 2017.

4. Hart M. Ultrarunning at a crossroads: is there a growing doping problem on the trails? Available at: http://running. competitor.com/2015/12/news/ultrarunning-at-a-crossroads-isthere-a-growing-doping-problem_141321. 2015. Accessed September 1, 2017.

5. Lazuras L, Barkoukis V, Rodafinos A, Tzorbatzoudis H. Predictors of doping intentions in elite-level athletes: a social cognition approach. J Sport Exerc Psychol. 2010; 32(5):694-710.

6. Alaranta A, Alaranta H, Holmila J, Palmu P, Pietilä K, Helenius I. Self-reported attitudes of elite athletes towards doping: differences between type of sport. Int J Sports Med. 2006;27(10):842-6.

7. Kurt A. When it comes to anti-doping, trail running is still a wild west. Available at: https://trailrunnermag.com/ people/culture/2299-anti-doping-efforts-trail-running. 2016. Accessed September 1, 2017.

8. Metzler B. Athletes, coaches, advocates support launch of clean sport collective. Available at: http://running.compet itor.com/2016/11/news/top-endurances-athletes-coaches-ad vocates-support-launch-clean-sport-collective_158168. 2016. Accessed September 1, 2017.

9. Baronner J. Race sets new standard against doping in trail running. Available at: http://www.runnersworld.com/trail- running/race-sets-new-standard-against-doping-in-trail-run ning. 2016. Accessed September 1, 2017.

10. Hollister J. ECS Clean Sport Policy. Available at: https:// www.thenorthface.com/about-us/news/2016/ecs-clean-sportpolicy.html. 2016. Accessed September 1, 2017.

11. Western States. Performance rules. Available at: http:// Www.wser.org/performance-rules/. 2016. Accessed September 1, 2017.

12. Bleakman DJ. Drugs in ultra running-global reader survey results. Available at: http://ultra168.com/2015/07/29/drug s-in-ultra-running-global-reader-survey-results/. 2015. Accessed September 1, 2017.

13. Torrence I. Performance enhancing drugs in ultramarathons. Available at: http://www.irunfar.com/2015/07/per formance-enhancing-drugs-in-ultramarathons.html. 2015. Accessed September 1, 2017.

14. Bleakman DJ. Drugs in ultrarunning study-use of banned substances in racing and training increases. Available at: https://ultra168.com/2016/07/27/drugs-in-ultrarunningstudy-use-of-banned-substances-in-racing-and-trainingincreases/. 2016. Available at: September 1, 2017.

15. Mazanov J, Huybers T, Connor J. Qualitative evidence of a primary intervention point for elite athlete doping. J Sci Med Sport. 2011;14(2):106-10.

16. Morente-Sanchez J, Zabala M. Doping in sport: a review of elite athletes' attitudes, beliefs, and knowledge. Sport Med. 2013;43(6):395-411.

17. Tavani A, Colombo P, Scarpino V, Zuccaro P, Pacifici R, La Vecchia C. Beliefs on and attitude toward doping use among athletes: an Italian survey. Ital J Public Health. 2012;9(4):1-7. (e8669).

18. Nature. A sporting chance. Nature. 2007;448(7153):512.

19. Petróczi A, Aidman E. Measuring explicit attitude toward doping: review of the psychometric properties of the Performance Enhancement Attitude Scale. Psychol Sport Exerc. 2009;10(3):390-6.

20. Morente-Sánchez J, Femia-Marzo P, Zabala M. Crosscultural adaptation and validation of the spanish version of the performance enhancement attitude scale (petróczi,). J Sports Sci Med. 2014;13(2):430-8.

21. Petroczi A, Aidman EV, Nepusz T. Capturing doping attitudes by self-report declarations and implicit assessment: a methodology study. Subst Abuse Treat Prev Policy. 2008;3(1):9.

22. Harris PA, Taylor R, Thielke R, Payne J, Gonzalez N, Conde JG. Research electronic data capture (REDCap)-a metadata-driven methodology and workflow process for providing translational research informatics support. J Biomed Inf. 2009;42(2):377-81.

23. Woodward M. Epidemiology: Study Design and Data Analysis. 3rd ed. Boca Raton, FL: CRC Press; 2013.

24. Bland JM, Altman DG. Cronbach's alpha. BMJ. 1997;314 (7080):572.

25. Aguilar M, Muñoz-Guerra J, Plata M del M, Del Coso J. Thirteen years of the fight against doping in figures. Drug Test Anal. 2017;9(6):866-9. 
26. Hilderbrand RL. High-performance sport, marijuana, and cannabimimetics. J Anal Toxicol. 2011;35(9):624-37.

27. Huestis MA, Mazzoni I, Rabin O. Cannabis in sport: anti-doping perspective. Sports Med. 2011;41(11):949-66.

28. Baron EP. Comprehensive review of medicinal marijuana, cannabinoids, and therapeutic implications in medicine and headache: What a long strange trip it's been. Headache. 2015;55(6):885-916.

29. US Anti-doping Agency. Effects of PEDs. Available at: http://www.usada.org/substances/effects-of-performanceenhancing-drugs/. 2016. Accessed September 1, 2017.

30. Swart J, Lamberts RP, Lambert MI, St Clair Gibson A, Lambert EV, Skowno J, et al. Exercising with reserve: evidence that the central nervous system regulates prolonged exercise performance. Br J Sport Med. 2009;43 (10):782-8.

31. Matava MJ. Ethical considerations for analgesic use in sports medicine. Clin Sports Med. 2016;35(2):227-43.

32. Pigozzi F, Di Gianfrancesco A, Zorzoli M, Bachl N, McDonagh D, Cummiskey J, et al. Why glucocorticosteroids should remain in the list of prohibited substances: a sports medicine viewpoint. Int $J$ Immunopathol Pharmacol. 2012;25(1):19-24.

33. Sjöqvist F, Garle M, Rane A. Use of doping agents, particularly anabolic steroids, in sports and society. Lancet. 2008;371(9627):1872-82.

34. Reardon C, Creado S. Drug abuse in athletes. Subst Abuse Rehabil. 2014;5:95-105.

35. Morente-Sánchez J, Zabala M. Knowledge, attitudes and beliefs of technical staff towards doping in Spanish football. J Sports Sci. 2015;33(12):1267-75.

36. Muwonge H, Zavuga R, Kabenge PA. Doping knowledge, attitudes, and practices of Ugandan athletes': a cross-sectional study. Subst Abuse Treat Prev Policy. 2015;10:37.

37. Uvacsek M, Nepusz T, Naughton DP, Mazanov J, Ránky MZ, Petróczi A. Self-admitted behavior and perceived use of performance-enhancing vs psychoactive drugs among competitive athletes. Scand J Med Sci Sports. 2011;21(2):224-34.

38. Henning AD. Health culture and running: non-elite runners' understandings of doping and supplementation. J Amat Sport. 2015;1(2):51-77. 